\title{
A Prospective Observational Study of Complications in 140 Sialendoscopies
}

\author{
Jokela, Johanna
}

2018-10

Jokela , J , Tapiovaara , L , Lundberg , M , Haapaniemi , A , Bäck , L \& Saarinen , R 2018 , '

A Prospective Observational Study of Complications in 140 Sialendoscopies ',

Otolaryngology - Head and Neck Surgery , vol. 159 , no. 4 , pp. 650-655 . https://doi.org/10.1177/019459981878241

http://hdl.handle.net/10138/305727

https://doi.org/10.1177/0194599818782418

publishedVersion

Downloaded from Helda, University of Helsinki institutional repository.

This is an electronic reprint of the original article.

This reprint may differ from the original in pagination and typographic detail.

Please cite the original version. 


\title{
A Prospective Observational Study of Complications in I 40 Sialendoscopies
}

\author{
Johanna Jokela, MD', Laura Tapiovaara, MD, PhD', \\ Marie Lundberg, MD, PhD', Aaro Haapaniemi, MD, PhD', \\ Leif Bäck, MD, PhD', and Riitta Saarinen, MD, PhD'
}

No sponsorships or competing interests have been disclosed for this article.

\begin{abstract}
Objectives. To evaluate the incidence and nature of complications associated with diagnostic and interventional sialendoscopies and to report intervention failures in a prospective setup.

Study Design. Prospective observational study.

Setting. Academic tertiary care university hospital.

Subjects and Methods. Patients who underwent diagnostic or interventional sialendoscopy between October 2015 and December 2016 were prospectively enrolled. Patient data, operation-related factors, treatment failures, and complications were recorded into a database and analyzed.
\end{abstract}

Results. A total of 140 sialendoscopies were attempted or performed on 118 patients; 67 (48\%) were for a parotid gland and 73 (52\%) for a submandibular gland. The sialendoscopy was interventional in 81 cases (58\%), diagnostic in 56 $(40 \%)$, and not possible to perform in $3(2.1 \%)$. A total of 21 complications were registered for 21 sialendoscopies (15\%) and 21 patients (18\%). The most common complication was infection, in 9 cases (6.4\%). Other observed complications were salivary duct perforation (4 cases), prolonged glandular swelling (3 cases), transient lingual nerve analgesia ( 2 cases), basket entrapment ( 2 cases), and transient weakness in the marginal branch of the facial nerve (I case). All complications were related to interventional procedures or papilla dilatation. Failure to treat occurred in 21 (15\%) sialendoscopies: sialendoscopy itself was unsuccessful in 3 cases, and an intended intervention failed in 18 cases.

Conclusion. Complications in sialendoscopy are usually related to interventional procedures. The complications are mainly minor and temporary but lead to additional follow-up visits, further treatments, and sometimes hospitalization. Sialendoscopic procedures are safe but not free of complications.

\section{Keywords}

sialendoscopy, complications, sialadenitis, sialoliths, salivary glands

Received February 12, 2018; revised May 10, 2018; accepted May 22, 2018.

$\mathrm{S}$ ialendoscopy has increased the treatment options of obstructive and inflammatory salivary gland disorders and has reduced the need for sialadenectomy, which is associated with a relatively high rate of complications, ${ }^{1,2}$ such as injuries to the marginalis mandibulae (1\%-8\%), hypoglossal (1\%-3\%), or lingual (2\%-6\%) nerves after submandibulectomy ${ }^{3}$ and temporal $(29 \%-65 \%)$ or permanent (1\%-3\%) facial nerve palsy and Frey's syndrome (3\%-30\%) after superficial or near-total parotidectomy. ${ }^{4-8}$

There is no consensus on how to define and grade complications. ${ }^{9}$ According to one proposed definition, complications are events leading to failure of the procedure, a second surgical procedure, a change in the surgical plan, or a deviation from the planned course of events as a result of the procedure itself. ${ }^{10,11}$ According to another proposed definition, complications are defined as any deviation from the normal postoperative course, but failure to cure and sequela (an after-effect of surgery that is inherent to the procedure) are distinguished from complications. ${ }^{9}$ Since both definitions have been used, reported sialendoscopy complication rates are not directly comparable. The variation is between $1 \%$ and $30 \%$ depending on the definition, sample size, and study population. ${ }^{10-16}$

Although proven to be efficient and safe, sialendoscopy is not free of complications. ${ }^{12,17}$ According to previous reports, most complications in sialendoscopy seem to be tolerable and temporary, such as minor ductal perforation, short-term lingual nerve paresthesia, postoperative infection, ductal stricture, ranula formation, or prolonged swelling. ${ }^{11,12}$ However, some of these complications may necessitate reinterventions. Major complications have also been described,

'Department of Otorhinolaryngology-Head and Neck Surgery, Helsinki University Hospital and University of Helsinki, Helsinki, Finland

\section{Corresponding Author:}

Johanna Jokela, MD, Department of Otorhinolaryngology-Head and Neck Surgery, Helsinki University Hospital, PO Box 263, Fl-00029 HUH, Helsinki, Finland.

Email: johanna.jokela@fimnet.fi 
including avulsion of the main duct and airway obstruction. ${ }^{10,15}$ All studies on complications in sialendoscopy have been retrospective thus far, which is a clear limitation and may lead to underestimation of the complication rates.

Our aim was to prospectively analyze the incidence and nature of complications associated with diagnostic and interventional sialendoscopies. In addition, we analyzed the causes of treatment failure.

\section{Materials and Methods}

Patients who underwent diagnostic or interventional sialendoscopy at the Department of Otorhinolaryngology-Head and Neck Surgery, Helsinki University Hospital, between October 2015 and December 2016 were prospectively enrolled. Exclusion criteria were age $<16$ years, insufficient Finnish or Swedish language skills, and lack of written informed consent. During the study period, 169 sialendoscopies were performed on 147 patients. Of these, 4 pediatric patients, 11 patients with insufficient language skills, and 14 patients who failed to prospectively recruit for the study or had not given written permission were excluded. The study was approved by the Operative Ethics Committee of Helsinki University Hospital (89/13/03/02/2011). The Declaration of Helsinki 2013 guidelines and protocols were followed. All enrolled patients provided informed consent.

Demographic and clinical data were collected, including age, sex, comorbidities (Charlson Comorbidity Index), ${ }^{18}$ American Society of Anesthesiologists physical status classification, body mass index, smoking status, surgical indication, operated gland, operation time, performing surgeon, sialendoscopy findings, type of procedure, type of anesthesia, use of antibiotics and corticosteroids, intra- and postoperative complications, treatment failures, and further treatments. A complication was defined as "any deviation from the normal intraoperative or postoperative course." When the original purpose of surgery was not achieved, it was classified as a failure to treat, not a complication. Postoperative swelling was not considered a complication but sequela, provided that further interventions were not required and swelling resolved within 5 days. To grade complications, we used the Clavien-Dindo classification of surgical complications, which consists of 7 grades (I, II, IIIa, IIIb, IVa, IVb, and V). The classification is based on the type of therapy needed to treat the complication. ${ }^{9,19}$

Four surgeons with 1 to 5 years of experience performed all operations. The ductal orifice was dilated, and the ductal system was explored under intermittent lavage with isotonic saline solution with $1 \%$ lidocaine to dilatate the ductal system and enhance visualization. All-in-1 endoscopes were used $(1.1$ or $1.3 \mathrm{~mm} ; 11573$ A and 11575 A, Karl Storz, Tuttlingen, Germany). Debris and mucus plugs were rinsed out, and strictures were opened by the endoscope, a salivary duct probe, or a microdrill. Sialoliths were removed with a Dormia basket, if permitted by the size and mobility of the stone. If not, an incision was made atop the stone in the submandibular duct. In parotid duct stones, an endoscopicassisted transfacial approach was used. Laser fragmentation, intraductal stonebreakers, or balloons were not available. An intraoperative prophylactic antibiotic (cefuroxime, $1.5 \mathrm{~g}$ intravenously) was recommended when the sialolith removal was planned through an intraoral incision or endoscopic-assisted transfacial approach. If the operation was difficult or prolonged, postoperative antibiotics (cephalexin for 5 to 7 days) were used at consideration of the surgeon. Steroid irrigation (1 mL of hydrocortisone, $125 \mathrm{mg}$ / $\mathrm{mL}$ ) was used in some patients with chronic inflammation without a sialolith. The procedure was considered interventional if sialolith removal or stricture dilatation was attempted or performed.

All patients received instructions to massage the treated gland to stimulate salivary flow postoperatively. All the patients received written and oral aftercare instructions, which included our emergency department contact information, description of normal postoperative recovery, and symptoms and signs of common complications related to sialendoscopy. The patients were strictly instructed to contact the emergency department of our hospital if they suspected any complication or deviation from normal postoperative course. Data on complications were recorded prospectively into a database.

Statistical analyses were performed with NCSS 8 statistical software (NCSS, LLC, Kaysville, Utah). Descriptive statistics were used to analyze the demographic and clinical characteristics. The results are given as means or percentages. Risk factors of complications were evaluated with Pearson's chi-square test, Fisher's exact test (when sample sizes were small), or equal-variance $t$ test. $P$ values $<.05$ were considered statistically significant.

\section{Results}

During the 15-month study period, 140 sialendoscopies were attempted or performed on 118 patients (mean age, 47 years; range, $19-86$ years; $69 \%$ women); 67 (48\%) were for a parotid gland and $73(52 \%)$ for a submandibular gland. Fifteen $(13 \%)$ patients underwent a procedure for multiple glands. Seven $(6 \%)$ patients underwent a resialendoscopy during the study period. Sialendoscopy itself was successfully performed in 137 of 140 cases $(98 \%)$. It was interventional in 81 cases (58\%), diagnostic in $56(40 \%)$, and not possible to perform in 3 ( $2 \%$; Figure I). The mean operation time was $32 \pm 21$ minutes, and local anesthesia was used in $131(94 \%)$ sialendoscopies. The majority $(\mathrm{n}=130$, $93 \%$ ) were performed in a fully equipped operation theater permitting conversion to general anesthesia if needed and $10(7 \%)$ in a polyclinic operating room. A follow-up visit was scheduled after $72(51 \%)$ procedures.

Sialoliths were verified endoscopically in 54 (39\%) sialendoscopies. Sialoliths were successfully removed in 42 cases; in 4 cases, a second procedure was necessary before the removal was complete and in $8(15 \%)$ cases the sialoliths were not possible to remove at all. The sialoliths were removed or tried to remove with a Dormia basket in 17 $(31 \%)$ cases, through an intraoral incision in $32(59 \%)$, and through endoscopic-assisted transfacial approach in 5 


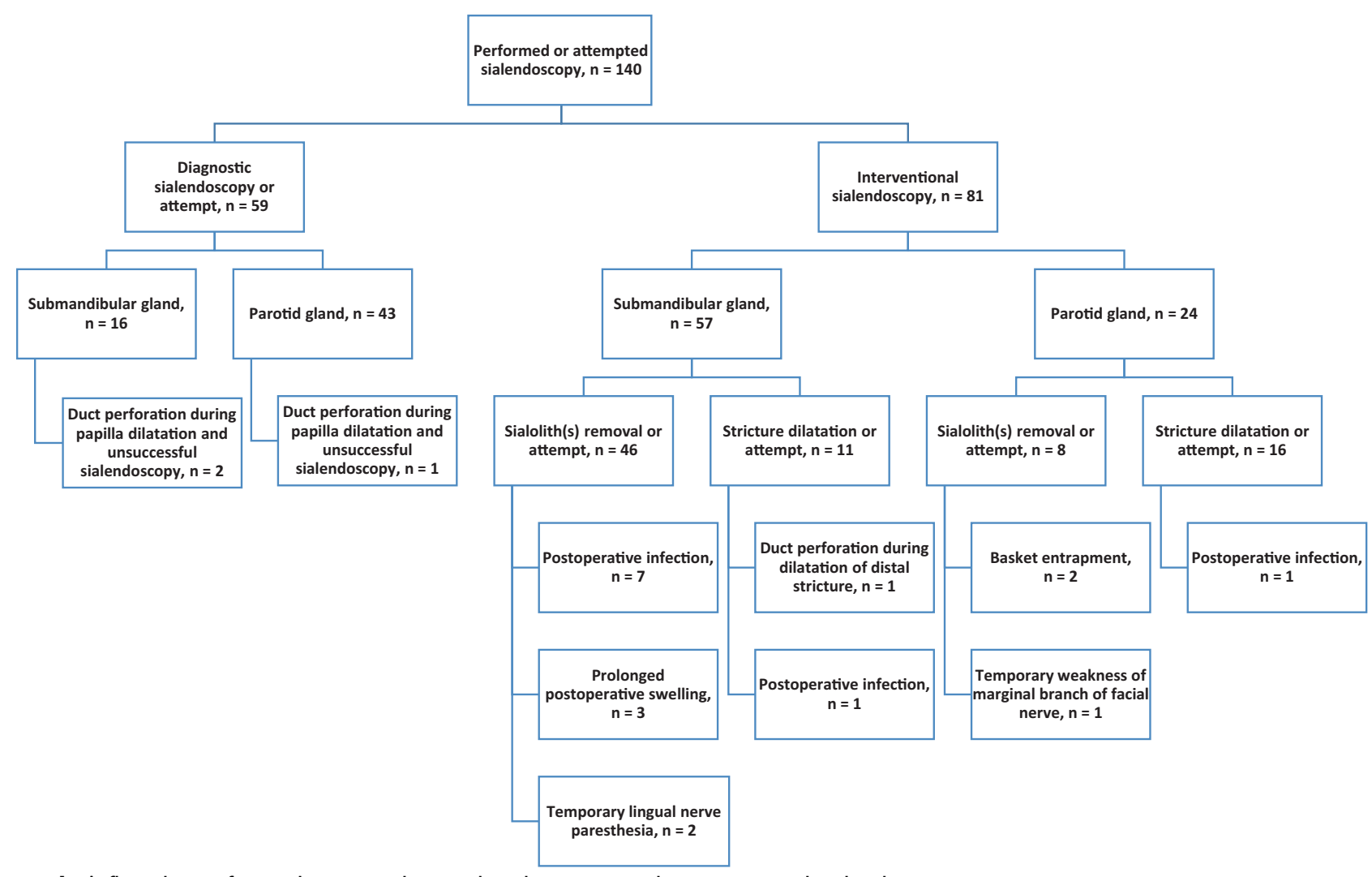

Figure I. A flowchart of complications observed in diagnostic and interventional sialendoscopies.

(9\%). Most strictures (21 of $27,78 \%$ ) were successfully dilated. Intraoperative prophylactic antibiotics were used in $43(31 \%)$ sialendoscopies. Five of these patients had an additional postoperative peroral course of antibiotics for infection prophylaxis. Intraductal steroid irrigation was used in $47(34 \%)$ cases of chronic sialadenitis without sialolithiasis.

A total of 21 complications were registered in 21 sialendoscopies (15\%) and 21 patients (18\%; Figure I). Nine (43\%) complications were intraoperative and $12(57 \%)$ postoperative. According to the Clavien-Dindo classification, 11 (52\%) complications were grade I and 10 (48\%) grade II. The most common complication was postoperative infection, in 9 cases $(6.4 \%)$. Of these, 2 needed hospitalization and intravenous antibiotic treatment, and 7 were treated with peroral antibiotics. Most infections (8 of 9, 89\%) occurred in submandibular glands, and all were related to interventional sialendoscopies. One parotid gland infection occurred after an unsuccessful attempt to dilate a stricture. Submandibular gland infections were mostly related to sialoliths.

Sialolithiasis increased the risk of infection significantly $(P=.012)$. Retained stones and intraoral stone removal from the posterior region had a statistically significant association with the development of an infection $(P=.004$ and $P=.048$, respectively). Prophylactic antibiotics in patients with sialolithiasis had no statistically significant effect on the incidence of postoperative infections $(P=.410)$. Three patients with sialolithiasis were referred to the emergency department because of continuous painful submandibular swelling 6 to 7 days after the procedure, but no signs of infection were detected. One of these patients was treated with a course of peroral steroids.

The second-most common complication was perforation near the orifice of the duct in 4 cases $(2.9 \%)$, of which 3 prevented proceeding with the sialendoscopy. Transient lingual nerve analgesia and paresthesia occurred in 2 cases after hilar stone removal through an intraoral incision. The other patient also had an impaired sense of taste, which recovered 1.5 months after the operation. In 2 procedures, the basket around a stone was entrapped in the parotid gland, and the operation was converted into an endoscopic-assisted transfacial approach under local anesthesia. One patient had transient weakness in the marginal branch of the facial nerve after endoscopic-transfacial sialolith removal. However, this weakness resolved within 5 hours without any treatment and was probably due to local anesthesia infiltration.

The performed or attempted intervention increased the risk of complications significantly in submandibular glands $(P=.016)$. Sialolith removal and stricture dilatation were independent risk factors for complication in the study population $(P=.001$ and $P=.032$, respectively). Patients with complications had a statistically longer mean operation time compared to patients without complications (56 and $27 \mathrm{~min}-$ utes, respectively; $P=.001$ ). Also, patients whose procedures were performed under general anesthesia had more 


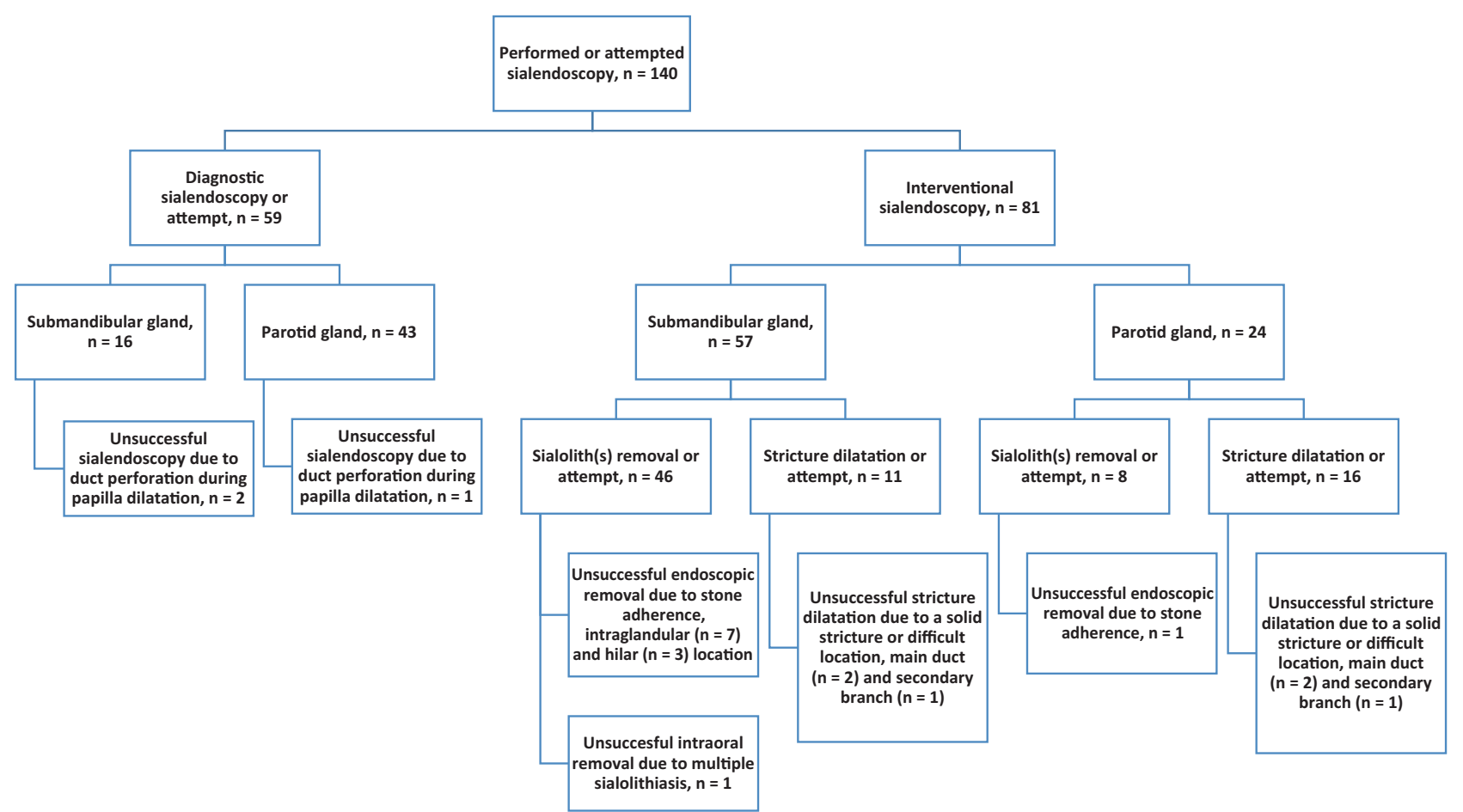

Figure 2. A flowchart of failures observed in diagnostic and interventional sialendoscopies.

often complications $(P=.011)$. Surgeon experience, patient age, American Society of Anesthesiologists class, Charlson Comorbidity Index, or tobacco smoking did not correlate with complication risk. Intraductal steroid administration was associated with a lower risk of complications $(P<$ .001 ), but this is explained by the lower number of interventions performed in this group.

In total, failure to perform a sialendoscopy or intended intervention occurred in $21(15 \%)$ sialendoscopies: 16 (22\%) submandibular and $5(7.5 \%)$ parotid. The most common causes were an unsuccessful attempt for endoscopic sialolith removal and dilatation of a solid stricture.

Figure 2 illustrates the observed failures.

\section{Discussion}

To our knowledge, this study is the first to prospectively register and report complications in sialendoscopy. All complications encountered were related to interventional procedures or papilla dilatation. Longer operation times and general anesthesia, which imply interventional and more challenging procedures, increased the risk for complications as well.

Complication rates between $2 \%$ and $13 \%$ have been reported for sialendoscopy. ${ }^{11,12,15,20}$ In some studies, a failure to perform an intervention has been categorized as a complication, raising the complication rates to $20 \%$ to $30 \% .{ }^{10,13}$ In our opinion, failure to achieve the original goal of the procedure should be classified as a failure to treat, not a complication, concurrent with the Clavien-Dindo classification of surgical complications. ${ }^{9}$

The most prevalent complications reported in sialendoscopy are intraoperative ductal perforations, ${ }^{12,13}$ postoperative strictures, ${ }^{11,17}$ and infections ${ }^{20,21}$ when the failure to perform an intervention is ruled out. Our results are similar, with the exception of strictures. Complication rate in our prospective set-up was $15 \%$, and failure to treat rate $15 \%$.

In our previous retrospective study, we reported an $8 \%$ complication rate, which is significantly lower than the rate observed in the current study. ${ }^{21}$ This, in our opinion, underlines the fact that prospective setup underestimates complication rates. Interestingly, the infection rate in both studies was approximately the same $(7.1 \%$ vs $6.4 \%)$ despite the increased use of prophylactic antibiotics in transoral and endoscopic-assisted transfacial stone removals. We had also set strict diagnostic criteria for postoperative infections to separate prolonged swelling from a bacterial infection.

Most infections (78\%) were associated with sialoliths: intraoral stone removal from a posterior region and retained stone fragments predisposed to infections. Reported postoperative infection rates vary from none to $11 \%$, and the predisposing factors have not been examined before. ${ }^{11,13,20}$ We observed no postoperative infections after diagnostic sialendoscopies or endoscopic sialolith removal. Thus, in our opinion, routine antibiotic use is unnecessary in these procedures. However, further studies regarding the need for prophylactic antibiotics are required.

Our second-most common complication was ductal perforation, which occurred while dilating the papilla in 4 glands $(2.9 \%)$. A perforation can also occur during an endoscopic intervention, ${ }^{22}$ but we did not have any ductal perforations further from the papilla. The reported perforation rates vary from $0 \%$ to $8 \% .{ }^{11,12,22,23}$ Karagozoglu et al 
observed that most ductal perforations occurred in the Wharton's duct, ${ }^{13}$ which might reflect the difficulties in the identification and dilatation of the papilla because of its location and loose tissue on the floor of the mouth. ${ }^{24}$

We classified prolonged or intense postoperative swelling needing interventions or additional follow-up visits as a complication. In the literature, there is no clear consensus on this, and in many studies postoperative swelling is not registered as a complication. Other complications confronted in our study were basket entrapment around an embedded stone and transient lingual nerve paresthesia that, although rare, are both well documented. ${ }^{25-27} \mathrm{We}$ recommend a careful assessment of the size and mobility of the stone and a priori plan for the potential conversion from a Dormia basket stone removal to an open procedure.

In endoscopic-assisted transfacial stone removal, complication rates are between $0 \%$ and $25 \%$, including salivary fistula, sialocele, duct perforation, and stricture. ${ }^{28-32} \mathrm{We}$ observed 1 case of self-limiting facial nerve paresthesia. No longer-lasting complications were observed, but the number of these procedures is limited in our study.

The complications of sialendoscopy are generally well tolerated and temporary, ${ }^{11,22}$ and our study supports this finding. We registered 2 complications that required hospitalization. Both patients had a postoperative infection of the submandibular region. Few potentially serious complications have been reported in the literature, such as airway obstruction after extravasation of the irrigation fluid into the floor of the mouth, ${ }^{15}$ pharyngeal swelling, ${ }^{33}$ and ductal avulsion. ${ }^{10}$ These complications are rare and were not encountered in our study.

The failure rates of diagnostic sialendoscopies range from $0 \%$ to $25 \%$. Failure is especially encountered among patients with Sjögren's syndrome. ${ }^{13,34,35}$ In a multicenter study of 1342 sialendoscopies, the failure to perform a sialendoscopy was $2.4 \%$, mainly due to complete ductal steno$\mathrm{sis}^{12}$ similar to our findings $(2.1 \%)$. Interestingly, the experience of the surgeon was not associated with the failure rate or complications in our study. This might be related to the fact that all our surgeons had at least 1 year of prior experience.

The present study has some limitations. Our study population was relatively small. Therefore, we did not encounter some well-known but uncommon complications. In addition, we were not able to perform any multivariate logistic regression analyses on the risk factors for complications, due to the small number of events.

Patients with uneventful and regular sialendoscopy were not scheduled for a routine follow-up visit, which is the current practice in our clinic. Complications appearing after discharge were registered based on the patients' contact to the department. However, when we screened all the medical records for quality assurance purposes, we found that all complications were caught according to patients' selfimposed contacts, and none were elicited during a routine follow-up visit.
Our study may also underestimate some complications that do not necessary cause any acute symptoms, such as partial postoperative strictures. Furthermore, most operations were performed under local anesthesia, and it is possible that procedures performed under general anesthesia have a different complication profile.

\section{Conclusion}

Sialendoscopy seems to be a safe treatment option for obstructive and inflammatory major salivary gland disorders. The complications are usually minor and sometimes self-limiting, but they may necessitate a change in surgical plan, multiple patient contacts, further treatments, or hospitalization. Most complications are related to interventional sialendoscopy and are rare in diagnostic sialendoscopy, where papilla dilatation seems to be the riskiest step. Infection was the most common complication observed in this study. Further studies concerning the need for prophylactic antibiotics are required.

\section{Author Contributions}

Johanna Jokela, designed study, analyzed data, main responsibility for writing the manuscript; Laura Tapiovaara, designed study, collected data, revised article; Marie Lundberg, designed study, collected data, revised article; Aaro Haapaniemi, designed study, collected data, revised article; Leif Bäck, designed study, revised article; Riitta Saarinen, designed study, collected data, revised article.

\section{Disclosures}

Competing interests: None.

Sponsorships: None.

Funding source: None.

\section{References}

1. Rasmussen ER, Lykke E, Wagner N, Nielsen T, Waersted S, Arndal H. The introduction of sialendoscopy has significantly contributed to a decreased number of excised salivary glands in Denmark. Eur Arch Otorhinolaryngol. 2016;273:2223-2230.

2. Kopec T, Wierzbicka M, Szyfter W, Leszczynska M. Algorithm changes in treatment of submandibular gland sialolithiasis. Eur Arch Otorhinolaryngol. 2013;270:2089-2093.

3. Capaccio P, Torretta S, Pignataro L. The role of adenectomy for salivary gland obstructions in the era of sialendoscopy and lithotripsy. Otolaryngol Clin North Am. 2009;42:1161-1171.

4. Patel RS, Low TH, Gao K, O'Brien CJ. Clinical outcome after surgery for 75 patients with parotid sialadenitis. Laryngoscope. 2007; 117:644-647.

5. Sharma R. Superficial parotidectomy for chronic parotid sialadenitis. Int J Oral Maxillofac Surg. 2013;42:129-132.

6. Nouraei SA, Ismail Y, McLean NR, Thomson PJ, Milner RH, Welch AR. Surgical treatment of chronic parotid sialadenitis. J Laryngol Otol. 2007;121:880-884.

7. Ruohoalho J, Makitie AA, Aro K, et al. Complications after surgery for benign parotid gland neoplasms: a prospective cohort study. Head Neck. 2017;39:170-176. 
8. Amin MA, Bailey BM, Patel SR. Clinical and radiological evidence to support superficial parotidectomy as the treatment of choice for chronic parotid sialadenitis: a retrospective study. Br J Oral Maxillofac Surg. 2001;39:348-352.

9. Dindo D, Demartines N, Clavien PA. Classification of surgical complications: a new proposal with evaluation in a cohort of 6336 patients and results of a survey. Ann Surg. 2004;240:205-213.

10. Walvekar R, Razfar A, Carrau R, Schaitkin B. Sialendoscopy and associated complications: a preliminary experience. Laryngoscope. 2008;118:776-779.

11. Nahlieli O. Complications of sialendoscopy: personal experience, literature analysis, and suggestions. J Oral Maxillofac Surg. 2015;73:75-80.

12. Gallo A, Capaccio P, Benazzo M, et al. Outcomes of interventional sialendoscopy for obstructive salivary gland disorders: an Italian multicentre study. Acta Otorhinolaryngol Ital. 2016; 36:479-485.

13. Karagozoglu KH, De Visscher JG, Forouzanfar T, van der Meij EH, Jager DJ. Complications of sialendoscopy in patients with Sjogren syndrome. J Oral Maxillofac Surg. 2017;75:978-983.

14. Nahlieli O, Baruchin AM. Long-term experience with endoscopic diagnosis and treatment of salivary gland inflammatory diseases. Laryngoscope. 2000;110:988-993.

15. Papadaki ME, McCain JP, Kim K, Katz RL, Kaban LB, Troulis MJ. Interventional sialoendoscopy: early clinical results. J Oral Maxillofac Surg. 2008;66:954-962.

16. Koch M, Zenk J, Bozzato A, Bumm K, Iro H. Sialoscopy in cases of unclear swelling of the major salivary glands. Otolaryngol Head Neck Surg. 2005;133:863-868.

17. Nahlieli O, Nakar LH, Nazarian Y, Turner MD. Sialoendoscopy: a new approach to salivary gland obstructive pathology. J Am Dent Assoc. 2006;137:1394-1400.

18. Charlson ME, Pompei P, Ales KL, MacKenzie CR. A new method of classifying prognostic comorbidity in longitudinal studies: development and validation. J Chronic Dis. 1987;40: 373-383.

19. Clavien PA, Barkun J, de Oliveira ML, et al. The ClavienDindo classification of surgical complications: five-year experience. Ann Surg. 2009;250:187-196.

20. Rasmussen ER, Arndal H, Rasmussen SH, Wagner N. Steady progress seen in endoscopic surgery on major salivary glands. Dan Med J. 2012;59:A4525.

21. Jokela J, Haapaniemi A, Ojala J, Makitie A, Saarinen R. Sialendoscopy in sialadenitis: an unselected cohort of 228 patients. Clin Otolaryngol. 2016;41:416-420.

22. Marchal F, Dulguerov P, Becker M, Barki G, Disant F, Lehmann W. Submandibular diagnostic and interventional sialendoscopy: new procedure for ductal disorders. Ann Otol Rhinol Laryngol. 2002;111:27-35.

23. Nahlieli O. Advanced sialoendoscopy techniques, rare findings, and complications. Otolaryngol Clin North Am. 2009;42: 1053-1072.

24. McGurk M. Commentary on: management of obstructive salivary disorders by sialendoscopy: a systematic review. $\mathrm{Br} \mathrm{J}$ Oral Maxillofac Surg. 2015;53:520-521.

25. Capaccio P, Gaffuri M, Torretta S, Pignataro L. Sialendoscopyassisted transfacial surgery for the removal of an iatrogenic foreign body in Stensen's duct: a stone and broken wire basket. J Laryngol Otol. 2016;130:501-505.

26. Capaccio P, Gaffuri M, Rossi V, Pignataro L. Sialendoscopeassisted transoral removal of hilo-parenchymal sub-mandibular stones: surgical results and subjective scores. Acta Otorhinolaryngol Ital. 2017;37:122-127.

27. Nahlieli O, Baruchin A. Endoscopic technique for the diagnosis and treatment of obstructive salivary gland diseases. J Oral Maxillofac Surg. 1999;57:1394-1401.

28. Ong AA, Carroll WW, Nguyen SA, Gillespie MB. Cost-effectiveness of transfacial gland-preserving removal of parotid sialoliths. Laryngoscope. 2017;127:1080-1086.

29. Karavidas K, Nahlieli O, Fritsch M, McGurk M. Minimal surgery for parotid stones: a 7-year endoscopic experience. Int $J$ Oral Maxillofac Surg. 2010;39:1-4.

30. Marchal F. A combined endoscopic and external approach for extraction of large stones with preservation of parotid and submandibular glands. Laryngoscope. 2007;117:373-377.

31. Koch M, Iro H, Zenk J. Combined endoscopic-transcutaneous surgery in parotid gland sialolithiasis and other ductal diseases: reporting medium- to long-term objective and patients' subjective outcomes. Eur Arch Otorhinolaryngol. 2013;270: 1933-1940.

32. Konstantinidis I, Chatziavramidis A, Iakovou I, Constantinidis J. Long-term results of combined approach in parotid sialolithiasis. Eur Arch Otorhinolaryngol. 2015;272:3533-3538.

33. Martins-Carvalho C, Plouin-Gaudon I, Quenin S, et al. Pediatric sialendoscopy: a 5-year experience at a single institution. Arch Otolaryngol Head Neck Surg. 2010;136:33-36.

34. Chuangqi Y, Chi Y, Lingyan Z. Sialendoscopic findings in patients with obstructive sialadenitis: long-term experience. $\mathrm{Br}$ J Oral Maxillofac Surg. 2013;51:337-341.

35. Pace C, Hwang KG, Papadaki M, Troulis M. Interventional sialendoscopy for treatment of obstructive sialadenitis. J Oral Maxillofac Surg. 2014;72:2157-2166. 